\title{
Chronic Disease Risk Typologies among Young Adults in Community College
}

Jayne K. Jeffries, PhD, MHS, MA

Leslie A. Lytle, PhD

Daniela Sotres-Alvarez, DrPH

Shelley Golden, PhD

Allison E. Aiello, PhD

Laura Linnan, ScD

Objectives: To address chronic disease risk holistically from a behavioral perspective, insights are needed to refine understanding of the covariance of key health behaviors. This study aims to identify distinct typologies of young adults based on 4 modifiable risk factors of chronic disease using a latent class analysis approach, and to describe patterns of class membership based on demographic characteristics, living arrangements, and weight. Methods: Overall, 441 young adults aged 18-35 attending community colleges in the Minnesota Twin Cities area completed a baseline questionnaire for the Choosing Healthy Options in College Environments and Settings study, a RCT. Behavioral items were used to create indicators for latent classes, and individuals were classified using maximum-probability assignment. Results: Three latent classes were identified: 'active, binge-drinkers with a healthy dietary intake' (13.1\%); 'non-active, moderatesmokers and non-drinkers with poor dietary intake' (38.2\%); 'moderately active, non-smokers and non-drinkers with moderately healthy dietary intake' (48.7\%). Classes exhibited unique demographic and weight-related profiles. Conclusions: This study may contribute to the literature on health behaviors among young adults and provides evidence that there are weight and age differences among subgroups. Understanding how behaviors cluster is important for identifying groups for targeted interventions in community colleges.

Key words: chronic disease; community college; health behavior; latent class analysis; young adult health

Am J Health Behav. ${ }^{\mathrm{TM}}$ 2018;42(2):71-84

DOI: https://doi.org/10.5993/AJHB.42.2.7

Y oung adulthood (ages 18-35) may provide important opportunities to prevent longterm risk behaviors and integrate health promotion activities that encourage a consistent pattern of healthy living. This time period is marked by important transitions, such as increased autonomy in decision-making and behavioral exploration and experimentation. This life stage may instigate and perpetuate potential health risk behaviors ${ }^{1,2}$ including decreased levels of physical activity, ${ }^{3}$ substance use, ${ }^{4}$ and poor dietary choices. ${ }^{5}$ These transition years represent a period in which individuals may relocate to new environments and create independent lifestyles and habits. Environments such as colleges and universities are ideal settings for health promotion due to their large young adult populations. ${ }^{6}$ Studies to improve understanding of how health-related behaviors occur in young adults are needed to identify effective intervention strategies to ultimately reduce the burden of chronic disease.

Health-related behaviors such as physical activity, tobacco and alcohol use, and diet are among the major factors that significantly contribute to preventable chronic disease morbidity and mortality in the United States (US). ${ }^{7}$ Studies have shown that few American adults meet national guidelines related to these 4 health behaviors. Reeves and Rafferty $^{8}$ report that in a national sample of adults, 
only 3\% met 4 healthy lifestyle characteristics, defined as not smoking, having a healthy weight (body mass index [BMI] of 18.5-25.0), consuming 5 or more fruits and vegetables a day, and engaging in regular physical activity (30 minutes, 5 times per week). Pronk et $\mathrm{al}^{9}$ found that only $10.8 \%$ of adults from a large midwestern health plan $(\mathrm{N}=585)$ met 5 lifestyle-related health factor recommendations (physical activity, non-smoking, high-quality diet, healthy weight, and moderate or no alcohol consumption). Lastly, Ford et $\mathrm{al}^{10}$ used data from the National Health and Nutrition Examination Survey and determined that only $6.8 \%$ of adults engaged in 4 healthy lifestyle factors (not smoking, adequate fruit and vegetable intake, adequate physical activity, and normal body weight).

Whereas it can be important to understand the effect of key risk behaviors independently of one another, behaviors seldom operate in isolation, and many of these health-related behaviors are related. For example, use of alcohol and tobacco ${ }^{11}$ or sedentary behavior and lack of physical activity often co-occur. ${ }^{12}$ Thus, to address individual chronic disease risk holistically from a behavioral perspective, insights are needed that move beyond single risk-factor assessment to examining the covariance of the 4 central modifiable behaviors that together contribute to chronic disease burden. A modest number of studies provide evidence that modifiable health-related risk factors such as tobacco and alcohol use, physical activity, and diet cluster. Among these studies, findings are fairly consistent and suggest that distinct clusters of individuals within a larger population can be identified. ${ }^{10,13,14}$ One of the most prevalent disease precursors for cardiovascular disease (CVD) risk is obesity, and trends indicate that obesity develops through gradual weight gain during early adulthood, with most obese individuals becoming so before age $35 .{ }^{15}$ Gaining weight can be particularly harmful for young adults, because it can be especially difficult to lose weight and maintain weight loss. ${ }^{16}$ Additionally, community college students are at high-risk for a range of damaging weightrelated outcomes - including higher prevalence of overweight and obesity, lower levels of physical activity, and higher intake of sugary beverages and fast-foods, compared to students attending 4-year colleges. ${ }^{17,18}$ Community college students may be at greater risk for obesity due to the additional de- mands that community college students often have as compared to 4-year college students. Community college students more often are working full time, are married and have dependent children, all factors that making healthy weight control more challenging. Identifying modifiable behavioral risk factors that cluster together and are associated with overweight and obesity would inform strategies to address young adult weight gain. Interventions focusing on young adults who pair their newly acquired independence with preventive approaches to obesity could lead to health-promoting behavioral patterns, ultimately decreasing the incidence of obesity and chronic disease.

Latent class analysis (LCA) is a method that lends itself to addressing the complexity of health-related behaviors through its ability to capture patterns or characteristics in each population. ${ }^{19}$ LCA can be used to identify the number of subpopulations - or typologies - and examines how those typologies may be associated with health outcomes. ${ }^{19}$ A review of the literature revealed several studies using LCA to observe clustering effects of multiple health-related behaviors. Héroux et $\mathrm{al}^{18}$ used 4 health-related behaviors (diet, smoking, fitness, and drinking alcohol) as indicators and found the existence of 2-classes among adults (ages 20-84); the results suggested that unhealthy behaviors and healthy behaviors cluster together. Furthermore, the authors found that the clustering of unhealthy behaviors did not vary according to chronic disease status. ${ }^{20}$ Leventhal et $\mathrm{al}^{21}$ used LCA to identify the patterns of modifiable risk factors for chronic disease (including alcohol abuse, drug abuse, nicotine dependence, obesity, and physical inactivity as indicators) in a population-based sample of US adults (18 years of age and older) and found 5 latent classes - obese, active non-substance abusers; nicotine-dependent, active, and non-obese; active, non-obese alcohol abusers; inactive, non-substance abusers; and active, polysubstance abusers, with each class displaying distinct demographic profiles. No published study to date has examined healthrelated behaviors among young adults in community colleges (ages 18-35) to assess chronic disease risk behavioral typologies.

Studies have identified behavioral causes for disease; however, greater attention is needed to specify how social conditions place individuals "at risk of risks." 22 Studies have focused on the health implica- 
tions of spatial environments such as neighborhoods or cities on health behaviors, ${ }^{23,24}$ but little research has focused on the most immediate social context in which individuals are embedded: the household. ${ }^{25}$ For young adults, living arrangements may be particularly salient to health because the household is an important environment for social relations that are encountered on a daily basis. ${ }^{5}$ Young adults have a variety of living arrangements, including living with their parents, with peers, independently, or with children. Individuals who live with parents report consuming fewer alcoholic drinks per week compared to their peers living away from home. ${ }^{26}$ Living independently or alone is a natural transition phase for most young adults and is a phase where young adults first take charge of their own food choices, ${ }^{27}$ decide how physically active to be, and choose how often to use tobacco and alcohol. These decisions often result in less healthful behavioral choices. ${ }^{28,29}$ Living with peers may create a context in which young adults might explore risky or health-damaging behaviors in context of their new relationships with others as peer group and media influence replaces parental guidance, increasing the probability of risky behavior. ${ }^{30,31}$ Other studies suggest that consuming alcohol is a social activity associated with living among peers. ${ }^{32}$ Marriage and the presence of children in the home are associated with fewer health-damaging behaviors in adults. ${ }^{33}$ However, people with children at home typically do not have higher levels of health than nonparents, possibly due to increased psychological distress. ${ }^{34}$

This study aims to identify distinct typologies of young adults based on the 4 modifiable risk factors of chronic disease using LCA, and to describe exploratory patterns of class membership based on demographic characteristics, living arrangements, and BMI. Identifying subgroups among young adults who share health-related behaviors would provide a deeper understanding of the needs of this population and aid in the development of effective interventions that can integrate the use of audience segmentation. Specifically, results of this study could inform strategies to prevent chronic disease by targeting young adults who cluster by certain health behaviors. Colleges and university systems could use this information to create campaigns and services to target particular segments of the student population to ensure shared risk behaviors in social contexts are addressed strategically.

\section{METHODS}

\section{Data Sources}

During fall 2011 and spring 2012, 441 students from 3 Minnesota community colleges enrolled in the Choosing Healthy Options in College Environments and Settings (CHOICES) study and completed baseline assessments. The CHOICES study, a randomized controlled trial designed to prevent unhealthy weight gain in young adults (ages 18-35) attending 2-year community colleges, was one of 7 EARLY (Early Adult Reduction of weight through LifestYle intervention) trials testing the effectiveness of technology-based obesity interventions. ${ }^{35}$ The intervention lasted 24 months and consisted of participation in an academic course and a social networking and support website. Evaluation measures were collected at baseline and at 4, 12, and 24 months. These included demographics, weightrelated behaviors, and other psychosocial factors. Participants received $\$ 100$ gift cards for participating in each outcome assessment. Bandura's Social Cognitive Theory was the theoretical framework chosen to guide the aims of this study that considered both the social environmental context and individual processes related to multiple health-related behaviors, ${ }^{36}$ thereby informing the included measures.

\section{Measures}

Indicators to assess the 4 modifiable health-related behaviors were developed from item responses from the CHOICES questionnaire recorded at baseline. The questionnaire asked young adults to recall past-month consumption of alcohol, fast-food consumption, sugar-sweetened beverage (SSB) consumption, past-week breakfast consumption, past-week physical activity, typical weekday and weekend sedentary behavior, and lifetime cigarette smoking. The CHOICES measures used have been validated and are reliable within this population. ${ }^{37-41}$ LCA uses categorical indicators; therefore, all variables were dichotomized (Table 1 ). Tobacco use included 2 classifications: current smoker and never smoker. ${ }^{42} \mathrm{~A}$ current smoker included respondents who reported smoking at least 100 cigarettes in their lifetime and who, at the time of survey, smoked either every day or some days. Participants were asked about their binge drinking behavior within the past 30 days. This item was dichoto- 
mized as those who did or did not binge drink in the past month according to the definition put forward by the National Institute Alcohol Abuse and Alcoholism. ${ }^{43}$

Three measures were used to represent diet intake: fast-food, breakfast, and sugar sweetened beverage (SSB) consumption. Fast-food dichotomization was informed through longitudinal evidence in a young adult population that suggested increased consumption of fast-food (1 time/week) was associated with a positive increase in BMI change over a 3-year period..$^{44}$ As for breakfast consumption, a meta-analysis of cross-sectional studies showed that the risk for overweight or obesity increased by $55 \%$ if breakfast is skipped. ${ }^{45}$ Breakfast consumption was dichotomized as eating breakfast (5 or more times a week) or not. Dichotomizing SSB consumption was based on evidence suggesting that individuals who consume sugary drinks regularly -1 to 2 cans per day or more - have a $26 \%$ greater risk of developing type 2 diabetes than people that rarely drink these sugary beverages. ${ }^{46}$

Four measures were used to represent physical activity behaviors. Self-reported physical activity was measured using the Paffenbarger Questionnaire ${ }^{39}$ to estimate leisure-time physical activity (LTPA) in minutes per week. Dichotomization was based on the physical activity guidelines and research showing that a total amount of 150 minutes a week of moderate-intensity aerobic activity reduces the risk of chronic disease. ${ }^{47}$ Three questions assessing weekday sedentary behavior, and 3 questions evaluating weekend sedentary behavior were combined to get a weekly total of sedentary time for a particular behavior. Time spent watching television was dichotomized as low amounts of television watched per day (2 hours or less) or not. This cut-point was chosen based on literature examining weight gain in adults and various amounts of time spent watching television. ${ }^{48,49}$

Due to a paucity of research focusing specifically on computer use and workplace weekly sitting recommendations, results from other studies evaluating work-related sitting were used as proxies to inform the dichotomous cut point. Three studies that examined the association between health behaviors and on time spent sedentary in a car ${ }^{50,51}$ or at work ${ }^{52}$ provide evidence that suggests uninterrupted weekly sitting more than 10 to 14 hours per week in a work-related environment may be health damaging. Therefore, selected cut-points included low sitting (12 hours or less per week) or high sitting while working (more than 12).

The categorical cut-point for sedentary time spent using the computer for non-work activities or playing video games was based on a study conducted among adults examining leisure-time Internet and computer use with weight-related outcomes, leisure-time physical activity, and other sedentary behaviors. Participants with high consumption (3 or more hours per week) of leisure-time computer use were significantly more likely to be overweight and obese than those who reported no leisure-time computer use. ${ }^{53}$ Therefore, this item was dichotomized as low use sitting while using the computer for non-work activities of playing video games (less than 3 hours per week) or high use ( 3 hours or more per week).

Self-report demographic information was collected from participants. Age was calculated through reported date of birth. "What is your gender" provided an individual's sex. Race/ethnicity was documented through "Which race best describes you?" then recoded as white/Caucasian or not. Living arrangements were collected with the question "With whom do you live?" Given the aforementioned evidence describing the health-protective effects of living with parents and the small cell sizes of individuals in the remaining categories (eg, living alone, with peers), responses were dichotomized as living with parents or not. Height and weight were measured by trained research staff using Shorr height boards (Irwin Shorr, Olney, MD) and Tanita scales (Tanita TBF-300A Body Composition Analyzer, Arlington Heights, IL). Height and weight measurements were used to calculate BMI $\left(\mathrm{kg} / \mathrm{m}^{2}\right)$.

\section{Data Analysis}

Data management and analyses were conducted using SAS v 9.4 (Cary, NC: SAS Institute Inc). A series of LCA models specifying latent class counts from 2 to 6 were fit. ${ }^{52}$ The 9 aforementioned indicator variables were used for the LCA (tobacco and alcohol use, diet, and physical activity) with no covariates included. Model estimation was repeated 1000 times using different starting values to detect any model identification problems. Five 


\begin{tabular}{|c|c|c|}
\hline \multicolumn{3}{|c|}{$\begin{array}{c}\text { Table } 1 \\
\text { LCA Indicator Variables }\end{array}$} \\
\hline \multicolumn{2}{|c|}{ LCA Indicator Variables } & \multirow{2}{*}{$\begin{array}{l}\text { Questions from CHOICES Survey } \\
\text { "Have you smoked at least } 100 \text { cigarettes in your entire } \\
\text { life?" and "Do you now smoke cigarettes every day, } \\
\text { some days, or not at all?" }\end{array}$} \\
\hline $\begin{array}{l}\text { 1. Tobacco } \\
\text { Use }\end{array}$ & $\begin{array}{l}\text { Frequency of cigarette use over participant's } \\
\text { lifetime } \\
1=\text { Not a Current Smoker } \\
2=\text { Current Smoker }\end{array}$ & \\
\hline $\begin{array}{l}\text { 2. Alcohol } \\
\text { Use }\end{array}$ & $\begin{array}{l}\text { Binge drank in the previous month } \\
1=\text { No } \\
2=\text { Yes }\end{array}$ & $\begin{array}{l}\text { "Considering all types of alcoholic beverages, how many } \\
\text { times during the past } 30 \text { days did you have } 4 \text { or more } \\
\text { drinks (for women) or } 5 \text { or more drinks (for men)?" }\end{array}$ \\
\hline $\begin{array}{l}\text { 3. Breakfast } \\
\text { Consumption }\end{array}$ & $\begin{array}{l}\text { Frequency of eating breakfast in a week } \\
1=5 \text { or more times per week } \\
2=4 \text { or less times per week }\end{array}$ & $\begin{array}{l}\text { "In a typical week, how many times do you eat } \\
\text { breakfast?" }\end{array}$ \\
\hline $\begin{array}{l}\text { 4. SSB } \\
\text { Consumption }\end{array}$ & $\begin{array}{l}\text { Frequency of SSB consumption over the } \\
\text { previous month } \\
1=\text { Low Consumption }(<1 / \text { day }) \\
2=\text { High Consumption }(>1 / \text { day })\end{array}$ & $\begin{array}{l}\text { "Over the past } 30 \text { days, how many times did you drink: } \\
\text { Soda or Pop? Sports drinks (such as Propel, PowerAde, } \\
\text { or Gatorade)? Energy drinks (such as Red Bull or Jolt)? }\end{array}$ \\
\hline $\begin{array}{l}\text { 5. Fast-food } \\
\text { Consumption }\end{array}$ & $\begin{array}{l}\text { Frequency of fast-food consumption over } \\
\text { the previous month } \\
1=\text { Low Consumption }(<1 / \text { week }) \\
2=\text { High Consumption }(>1 / \text { week })\end{array}$ & $\begin{array}{l}\text { Over the past } 30 \text { days, how many times did you buy } \\
\text { fast-food at a fast-food restaurant, such as McDonald's, } \\
\text { Burger King, Arby's, Wendy's, Hardee's, Taco Bell, } \\
\text { Taco Johns, Chipotle, KFC, Pizza Hut, Panera, Quiznos, } \\
\text { Noodles \& Company, Bruegger's Bagels?” }\end{array}$ \\
\hline $\begin{array}{l}\text { 6. Leisure } \\
\text { Time Physical } \\
\text { Activity }\end{array}$ & $\begin{array}{l}\text { Reported minutes of leisure time physical } \\
\text { activity over a participant's typical week } \\
1=\text { Meets Guidelines }(150 \text { min }+/ \text { week }) \\
2=\text { Does Not Meet Guidelines ( } 149 \text { min or } \\
\text { less/week) }\end{array}$ & $\begin{array}{l}\text { Self-reported weekly leisure time physical activity in } \\
\text { minutes was measured using the Paffenbarger } \\
\text { Questionnaire } 39\end{array}$ \\
\hline $\begin{array}{l}\text { 7. Seated TV } \\
\text { Watching }\end{array}$ & $\begin{array}{l}\text { Frequency of TV watching over a participant's } \\
\text { typical week } \\
1=\text { Low }(<2 \text { hours per day }) \\
2=\text { High }(>2 \text { hours per day })\end{array}$ & $\begin{array}{l}\text { "On a typical weekday (or weekend day), how much } \\
\text { time do you spend (from when you wake up until you go } \\
\text { to bed) sitting while watching television?" }\end{array}$ \\
\hline $\begin{array}{l}\text { 8. Seated } \\
\text { Computer } \\
\text { Use for } \\
\text { Work }\end{array}$ & $\begin{array}{l}\text { Frequency of computer use for work over a } \\
\text { participant's typical week } \\
1=\text { Low ( } 12 \text { hours or less per week) } \\
2=\text { High (More than } 12 \text { hours per week) }\end{array}$ & $\begin{array}{l}\text { "On a typical weekday (or weekend day), how much } \\
\text { time do you spend (from when you wake up until you } \\
\text { go to bed) sitting at work/school doing computer work } \\
\text { (email, word or data processing, etc.)?" }\end{array}$ \\
\hline $\begin{array}{l}\text { 9.Seated } \\
\text { Computer } \\
\text { Use for } \\
\text { Non-Work }\end{array}$ & $\begin{array}{l}\text { Frequency of computer use for non-work or } \\
\text { activities over a participant's typical week } \\
1=\text { Low ( }<3 \text { hours per week) } \\
2=\text { High ( } 3 \text { hours or more per week })\end{array}$ & $\begin{array}{l}\text { "On a typical weekday (or weekend day), how much } \\
\text { time do you spend (from when you wake up until you go } \\
\text { to bed) sitting while using the computer for } \\
\text { non-work/non-school activities or playing video games?" }\end{array}$ \\
\hline Tote. & ed beverages & \\
\hline
\end{tabular}

factors were considered in model selection including: Akaike's Information Criterion (AIC), ${ }^{55}$ adjusted Bayesian Information Criterion (BIC), ${ }^{56}$ the likelihood-ratio value $\left(G^{2}\right)$, entropy, ${ }^{57}$ and model interpretability or the notion that it should be possible to meaningfully describe each typology..$^{58}$ The appropriate number of classes can be determined by comparing the goodness-of-fit statistics. If the $\mathrm{G}^{2}$ estimates are less than the model's degrees of freedom, the model is identified as having a reasonably good fit, with lower values of AIC and BIC preferred..$^{59}$ Entropy gives an idea of how well the classification applies, with values approaching 1 indicating clear delineation of classes. ${ }^{57}$

Following the estimation of latent classes and selecting the best model to represent the data, latent classes were then tested through measurement invariance to ensure the classes have the same meaning in those living with parents and those not living with parents. Young adults were then assigned to the class in which they had the highest probability of membership. ${ }^{60}$ Classes were described by their 
Figure 1

CONSORT Diagram: Flow of Participants through the CHOICES Study

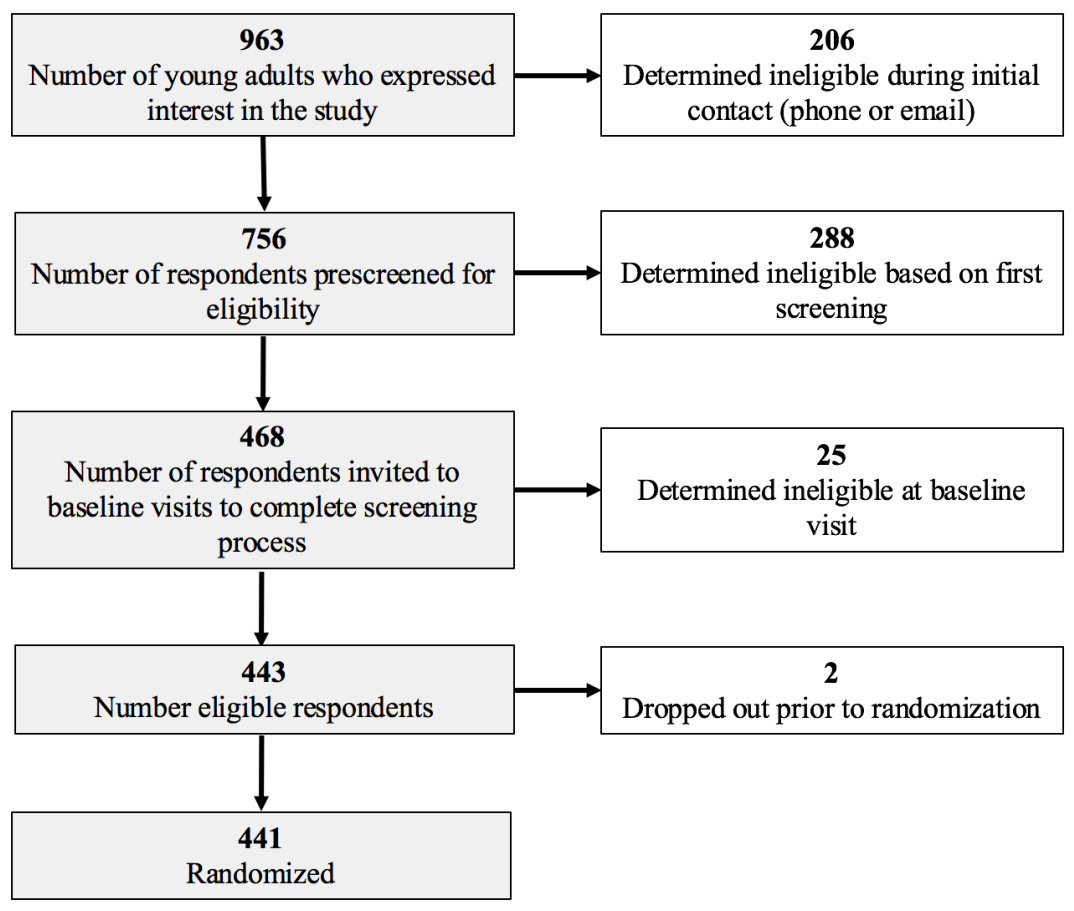

demographic factors, living arrangements, and BMI, and relationship of these predictors with the probability of class membership were tested through a multinomial logistic regression model, in which the dependent variable was latent class membership. ${ }^{58}$ For each variable, statistical significance $(p<.05)$ provides evidence that the independent variable is a significant predictor of class membership. ${ }^{58}$

\section{RESULTS}

\section{Descriptive Characteristics}

The CONSORT diagram (Figure 1) illustrates recruitment of the study sample. Table 2 details the characteristics of the 441 young adults comprising the sample. The sample was primarily female and white with a mean BMI of 25.4. Slightly more than half lived with their parents. About $16 \%$ of the sample were current cigarette smokers and approximately $25 \%$ reported binge drinking in the past month. Half of the sample reported poor diet behaviors - including high fast-food intake, high
SSB intake, and skipping breakfast. Fifty percent of the sample met the physical activity guidelines. Thirty-five percent of young adults watched more than 2 hours of TV per day. High sedentary behavior for playing video games or being on the computer for non-work purposes was reported by $70 \%$ of young adults. Fifty percent of the sample had high sedentary behavior based on the amount of time they reported spent on the computer for school or work purposes.

\section{Latent Class Estimation}

Based on the model fit indices (Table 3), a 3-class model represented the optimal balance of model fit and interpretability. The 3-class model was favored over the 2-class model when considering the $\mathrm{G}^{2}$, $\mathrm{AIC}$, entropy, adjusted $\mathrm{BIC}$, and depicting unique health behavior response patterns for the young adult population.

\section{Latent Class Typologies}

The item-response probabilities for each health- 
Table 2

Baseline Characteristics of Young Adults Attending a 2-year College ( $N=441)$

\begin{tabular}{|c|c|}
\hline Variable in Model & $\begin{array}{c}\text { Frequency (\%) or } \\
\text { Mean (SD) }\end{array}$ \\
\hline Age, years & $22.7(5)$ \\
\hline \multicolumn{2}{|l|}{ Sex } \\
\hline Female & $67.6 \%$ \\
\hline \multicolumn{2}{|l|}{ Race } \\
\hline White & $72.6 \%$ \\
\hline Body Mass Index & $25.4(3.8)$ \\
\hline \multicolumn{2}{|l|}{ Living Arrangements } \\
\hline Living with Parents & $54.4 \%$ \\
\hline \multicolumn{2}{|l|}{ Tobacco Use } \\
\hline Current Smoker & $16.4 \%$ \\
\hline \multicolumn{2}{|l|}{ Alcohol Use in the Past Month } \\
\hline Binge Drinking & $24.3 \%$ \\
\hline \multicolumn{2}{|l|}{ Diet and Energy Intake } \\
\hline High Fast-food Intake ( $\geq 1$ /week) & $50.6 \%$ \\
\hline High SSB Intake ( $\geq 1$ /day) & $48.8 \%$ \\
\hline Skips Breakfast (Eats 0-4 times/week) & $48.5 \%$ \\
\hline \multicolumn{2}{|l|}{ Physical Activity } \\
\hline Meets Guidelines ( $\geq 150$ minutes/week) & $50.1 \%$ \\
\hline High TV Watching (2 hours or more/day) & $35.4 \%$ \\
\hline High Sedentary Time for Work Computer Use (More than 12 hours/week) & $49.9 \%$ \\
\hline High Sedentary Time for Non-work Computer Use (3 hours or more/week) & $70.7 \%$ \\
\hline
\end{tabular}

Note.

SSB: sugar-sweetened beverages

related behavior conditional in the latent classes are in Table 4. The descriptive characteristics of each of the classes are presented in Table 5. These probabilities and descriptions can be used to characterize the classes. The 3 distinct classes identified in this sample include:

Class 1 (active, binge-drinkers with a healthy dietary intake) accounted for $13.1 \%$ of the sample, making this the smallest class among all the classes. Individuals in this class were distinguished by the

Table 3

Model Fit Statistics for Latent Class Models among Young Adults $(\mathrm{N}=441)$

\begin{tabular}{lcccccc}
\hline $\begin{array}{l}\text { Number of } \\
\text { Classes }\end{array}$ & $\mathbf{G}^{\mathbf{2}}$ & df & AIC & Adjusted BIC & Log-Likelihood & Entropy \\
\hline $\mathbf{2}$ & 454.01 & 492 & 492.01 & 509.41 & $\mathbf{- 2 4 2 7 . 4 9}$ & .54 \\
\hline $\mathbf{3}$ & $\mathbf{4 1 8 . 4 1}$ & 482 & 476.41 & $\mathbf{5 0 2 . 9 6}$ & -2409.69 & .73 \\
\hline $\mathbf{4}$ & 395.61 & 472 & 473.61 & 509.31 & -2398.29 & .70 \\
$\mathbf{5}$ & 371.22 & 462 & $\mathbf{4 6 9 . 2 2}$ & 514.08 & -2386.09 & .68 \\
$\mathbf{6}$ & 351.46 & 452 & 469.46 & 523.47 & -2376.21 & $\mathbf{. 7 6}$ \\
\hline
\end{tabular}




\section{Table 4}

Conditional-Response Probabilities from Latent 3-class Model of

Chronic Disease Risk Behavioral Typologies $(\mathrm{N}=441)$

\begin{tabular}{|c|c|c|c|c|}
\hline & \multicolumn{3}{|c|}{ Latent Class } & \multirow[b]{2}{*}{ OVERALL } \\
\hline & $\begin{array}{c}\text { CLASS } 1 \\
13.1 \% \\
\end{array}$ & $\begin{array}{c}\text { CLASS } 2 \\
38.2 \% \\
\end{array}$ & $\begin{array}{c}\text { CLASS } 3 \\
48.7 \% \\
\end{array}$ & \\
\hline \multicolumn{5}{|l|}{ Tobacco Use } \\
\hline Current Smoker & .321 & .257 & .048 & .164 \\
\hline \multicolumn{5}{|l|}{ Alcohol Use in the Past Month } \\
\hline Binge Drinker & .917 & .316 & .003 & .243 \\
\hline \multicolumn{5}{|l|}{ Diet and Energy Intake } \\
\hline High Fast-food Intake & .246 & .822 & .327 & .506 \\
\hline High Sugary Beverage Intake & .076 & .898 & .292 & .488 \\
\hline Does Not Eat Breakfast Regularly & .209 & .734 & .364 & .485 \\
\hline \multicolumn{5}{|l|}{ Physical Activity } \\
\hline Fails to Meet Recommended Guidelines & .332 & .629 & .433 & .499 \\
\hline High weekly TV watching & .264 & .487 & .274 & .354 \\
\hline High non-work computer use & .691 & .763 & .668 & .707 \\
\hline High computer use for work & .455 & .461 & .541 & .499 \\
\hline
\end{tabular}

Note.

$\mathrm{G}^{2}=418.41$ with $482 \mathrm{df}$; $\mathrm{AIC}=\mathbf{4 7 6 . 4 1}$; Adjusted $\mathrm{BIC}=\mathbf{5 0 2 . 9 6}$

highest probability of binge drinking in the past month (item-response probability of .92) and cigarette smoking (.32). Individuals in this class did not consume much fast-food (.24), did not drink a lot of SSBs (.07), or tend to skip breakfast (.21). Less than half of young adults in this class failed to meet recommended guidelines for physical activity (.33). A high proportion of time was spent sedentary doing non-work on the computer or playing video games (.69). This class was mainly female (77\%) and most lived independently from their parents $(64.2 \%)$ and had an average BMI of $25.5(\mathrm{SD}=3.5)$.

Class 2 (non-active, moderate-smokers and nondrinkers with poor dietary intake) included 38.2\% of the sample. In this class, young adults were sometimes likely to binge drink in the past month

\begin{tabular}{|c|c|c|c|c|}
\hline \multicolumn{5}{|c|}{$\begin{array}{c}\text { Table } 5 \\
\text { Chronic Disease Risk Behavioral Typology Characteristics }(\mathrm{N}=441)\end{array}$} \\
\hline & $\begin{array}{l}\text { CLASS } 1(\mathrm{~N}=53) \\
\text { Frequency }(\%) \text { or } \\
\text { Mean (SD) }\end{array}$ & $\begin{array}{l}\text { CLASS } 2(\mathrm{~N}=164) \\
\text { Frequency }(\%) \text { or } \\
\text { Mean (SD) }\end{array}$ & $\begin{array}{l}\text { CLASS } 3(\mathrm{~N}=224) \\
\text { Frequency }(\%) \text { or } \\
\text { Mean (SD) }\end{array}$ & $\begin{array}{l}\text { OVERALL } \\
\text { Frequency (\%) or } \\
\text { Mean (SD) }\end{array}$ \\
\hline Age, years & $25.2(5.6)$ & $22.4(4.8)$ & $22.4(4.8)$ & $22.7(5)$ \\
\hline \multicolumn{5}{|l|}{ Sex } \\
\hline Female & $77.3 \%$ & $61.5 \%$ & $69.6 \%$ & $67.6 \%$ \\
\hline \multicolumn{5}{|l|}{ Race } \\
\hline White & $83 \%$ & $72.6 \%$ & $70 \%$ & $72.6 \%$ \\
\hline Body Mass Index & $25.5(3.5)$ & $26(3.9)$ & $24.9(3.7)$ & $25.4(3.8)$ \\
\hline \multicolumn{5}{|l|}{ Living Arrangements } \\
\hline Living with Parents & $35.8 \%$ & $54.8 \%$ & $58.5 \%$ & $54.4 \%$ \\
\hline
\end{tabular}




\begin{tabular}{|c|c|c|c|}
\hline \multicolumn{4}{|c|}{$\begin{array}{c}\text { Table } 6 \\
\text { Predictors of Class Membership Using Multinomial Logistic Regression }\end{array}$} \\
\hline Class & Effect & OR $(95 \%$ CI $)$ & aOR $(95 \% \mathrm{CI})$ \\
\hline \multicolumn{4}{|c|}{ Class 3 as Comparison Class } \\
\hline \multirow[t]{5}{*}{ Class 1} & BMI & $1.04(.96-1.13)$ & $1.04(.95-1.13)$ \\
\hline & Living Arrangements (reference is parents) & $2.52(1.35-4.69)^{* *}$ & $1.62(.72-3.63)$ \\
\hline & Male (reference is female) & $.67(.33-1.36)$ & $.73(.35-1.52)$ \\
\hline & White (reference is non-white) & $2.09(.96-4.51)$ & $2.09(.95-4.59)$ \\
\hline & Age (years) & $1.10(1.04-1.16)^{* * *}$ & $1.07(.99-1.14)$ \\
\hline \multirow[t]{5}{*}{ Class 2} & BMI & $1.08(1.02-1.14)^{* *}$ & $1.08(1.02-1.14)^{* *}$ \\
\hline & Living Arrangements (reference is parents) & $1.16(.77-1.74)$ & $1.29(.77-2.16)$ \\
\hline & Male (reference is female) & $1.43(.94-2.19)$ & $1.39(.90-2.15)$ \\
\hline & White (reference is non-white) & $1.13(.72-1.76)$ & $1.09(.69-1.72)$ \\
\hline & Age (years) & $1.00(.96-1.05)$ & $.99(.94-1.04)$ \\
\hline \multicolumn{4}{|c|}{ Class 2 as Comparison Class } \\
\hline \multirow[t]{5}{*}{ Class 1} & BMI & $.96(.89-1.05)$ & $.97(.89-1.05)$ \\
\hline & Living Arrangements (reference is parents) & $2.18(1.15-4.13)^{*}$ & $1.25(.55-2.86)$ \\
\hline & Male (reference is female) & $.47(.22-.96)^{*}$ & $0.52(.25-1.10)$ \\
\hline & White (reference is non-white) & $1.85(.83-4.09)$ & $1.92(.85-4.32)$ \\
\hline & Age (years) & $1.10(1.04-1.16)^{* * *}$ & $1.08(1.00-1.16)^{*}$ \\
\hline \multicolumn{4}{|c|}{$* p<.05, * * p<.01, * * * p<.001$} \\
\hline \multicolumn{4}{|c|}{$\begin{array}{l}\text { Note. } \\
\text { BMI: body mass index }\end{array}$} \\
\hline
\end{tabular}

(.32) and smoke cigarettes (.26). Young adults in this class were likely to skip breakfast (.73), drink a high quantity of sugary-beverages (.89), have a high frequency of fast-food intake (.82), fail to meet physical activity guidelines (.63), and have a high proportion of time spent sedentary doing non-work on the computer or playing video games (.76). Half of the individuals in this class lived with parents $(54.8 \%)$ and approximately $61 \%$ were female.

Class 3 (moderately active, non-smoking and non-drinkers with moderately healthy dietary intake) was the largest class and accounted for $48.7 \%$ of the sample. Young adults in this class did not smoke or drink. Less than half of the sample within this class have a high frequency of fast-food intake (.33), high SSB consumption (.29), and are likely skip breakfast (.36). Fewer than half failed to meet recommended guidelines (.43). This class has a high proportion of young adults spending time doing non-work on the computer/playing video games (.67) and using the computer for work/ school (.54). Approximately $60 \%$ of individuals in this class were normal weight (BMI of 24.9 [SD = 3.7]), approximately $70 \%$ female, and most lived with parents $(58.5 \%)$.

\section{Comparisons of Outcomes by Class}

Measurement invariance was used to explore differences between those living with parents and those not living with parents. Results indicated that the latent class membership probabilities were similar for each group (data not shown); therefore; the living arrangement variable was used as a covariate. Results from the multinomial logistic regression are presented in Table 6, reporting unadjusted and adjusted effects. Unadjusted models only include a single independent variable regressed on class membership. Adjusted models include all independent variables to predict class membership. Evidence from the adjusted models suggested there were 
meaningful differences for BMI and age between latent classes, but not for living arrangements. For each additional unit increase in BMI, individuals are approximately $8 \%$ more likely to be in Class 2 versus Class $3(\mathrm{OR}=1.08 ; \mathrm{p}=.006)$ controlling for living arrangements, sex, race, and age. For each additional year in age, individuals are approximately $8 \%$ more likely to be in Class 1 versus Class 2 (OR $=1.10 ; \mathrm{p}=.039)$ holding all else constant.

\section{DISCUSSION}

The aim of this study was to identify subgroups of young adults with respect to their patterns of tobacco and alcohol use, dietary intake, and physical activity behaviors to further understand behavioral chronic disease risk. Results suggested meaningful clusters of lifestyle characteristics occur among young adults. This analysis identified 3 latent classes of modifiable health-related behaviors in young adults in community colleges: (1) active, binge-drinkers with healthy dietary intake; (2) non-active, moderate-smokers and non-drinkers with poor dietary intake; and (3) moderately active, non-smokers, non-drinkers with a moderately healthy dietary intake. These classes differed significantly by age and weight. Contrary to our hypothesis, the classes did not differ by living arrangement.

The classes yielded some similarities and differences. All 3 classes were characterized by their high use of the computer for non-work/non-school activities or playing video games, reflecting high prevalence of these behaviors in all young adults in our sample. Class 1 appeared to represent community college students who are older, active, and eat a relatively healthy diet based on their consumption of fast-food, SSBs, and breakfast, but have the highest probability of being binge drinkers and smokers among the 3 groups. Those in Class 2 engaged in unhealthy behaviors across all 4 behavioral categories examined. These students are neither active nor eating a healthy diet and have a moderate probability of smoking and binge drinking. This group can be viewed as the high-risk group for weight gain particularly regarding traditional lifestyle behaviors (diet and physical activity), and had the highest proportion of males. Class 3 appeared to represent the healthiest group of students with probabilities favoring not smoking or binge drinking, a more healthful diet, and greater levels of physical activ- ity - except for sedentary behavior. The 3 groups differed significantly in their obesity risk with those students in Class 2 having the highest mean BMI; BMI was similar in Class 1 and 3.

To our knowledge, there has been one prior study that has assessed clusters of health behaviors in a college population, but none among community college students. Research in a US college sample that examined cancer risk behaviors found that unhealthy diet was high among students universally. ${ }^{61}$ The 4 clusters in this college sample found evidence for (1) unhealthy diet; (2) unhealthy diet and physical inactivity; (3) unhealthy diet, physical inactivity, and overweight/obesity; and (4) tobacco use, binge drinking, unhealthy diet, and physical inactivity. ${ }^{61}$ This research has similar findings as the current study. In particular, Class 2 characterized by high BMI, physical inactivity, and poor diet quality are similar as the patterning of overweight/ obesity clustered with those who have unhealthy diet and being physically inactive. ${ }^{61}$ However, there are 2 distinct findings that add to this literature: sedentary behavior (differing from low diet quality) and Class 1 - those who engage in mostly healthy behaviors but have a high proportion of binge drinking. Current findings might diverge from the other study due to measurement differences or by behaviors studied.

Although there were no significant differences between the among in living arrangements, Class 1 descriptively had the fewest group members living with their parents, whereas both Class 2 and 3 had more than half of the group members living with their families. It is difficult to explain why Class 2 and 3 behavioral risks look so different despite the fact that the majority in both groups live with their parents. This stands in contrast to the expectation that living with one's parents may provide an environment where it is easier to make healthier choices. Future studies could examine these differences; it may be that the students in Class 2 are living under their parents' roofs but are otherwise not engaged in family life or habits that support healthy behaviors, whereas students in Class 3 are more engaged in the healthy behaviors that often accompany family life. Another possible explanation between the 2 classes could include varying environmental stimuli. Past research suggests that dietary behaviors can be influenced through envi- 
ronmental stimuli - where availability of foods and alcohol $^{62}$ and/or observing others eat ${ }^{62}$ or smoke ${ }^{63}$ can impact behavior. Young adults are likely to be influenced more by their social versus physical environments during this life course stage, because their physical environments may be diverse.

There are limitations to this research. The sample included a large proportion of females (68\%), consisted primarily of white participants (73\%), and was composed of a self-selected convenience sample of community college students. These sample characteristics limit the generalizability of our findings. The sample participating in the CHOICES study was comprised of slightly more females and more underrepresented minorities than the population of students attending the 3 community colleges. ${ }^{64}$ This study is also cross-sectional, so we know nothing about the stability of these classes over time. This is especially important for the individuals in Class 1 who have a high endorsement of binge drinking, which may be commonly observed in the young adulthood years. Though dichotomizing variables is an approach that is commonly used in LCA and may aid in the interpretability and communications of findings, there may be some loss of sensitivity that results from categorizing the data in this way. As with all self-report data, over- or under-reporting could have occurred, which has implications for the classes; however, the use of valid measurements hopefully minimized this possibility. This study also has several strengths, such as the use of data from community colleges and the application of a current analytic methods.

\section{Implications}

The results of this study lead to 3 different intervention implications. First, each class is characterized by the presence of high amounts of sedentary behavior spent on the computer. In fact, more than $70 \%$ of the sample reported more than 2 hours of non-work time with a computer. This underscores the potential utility of a community college-wide intervention that replaces time spent on the computer playing video games or other non-work with non-sedentary behavior. Young adults often play online/video games for immersion experiences, achievement, and social engagement purposes. ${ }^{65}$ Non-sedentary lifestyles that serve these purposes could be facilitated through the creation of physi- cal activity opportunities such as group intramurals, walking/running clubs, fitness classes, or the use of activity trackers that have built-in competitions with friends and achievement features. Future research should attempt to understand key determinants of this behavior and find ways to motivate young adults to attend and participate in non-sedentary activities.

Secondly, and specifically for those individuals who are engaging in physically active lifestyles, but also in binge drinking and smoking, intervention strategies should focus on substance use behaviors. Different social mechanisms might be asserting influence on this group such as affiliations with key organizations or social networks, outside of living arrangements, if, for example, students in this class participate in sports leagues or community social groups that organize around fitness followed by alcohol consumption. Future research should examine this premise, and if confirmed, alcohol-specific strategies and information could be tailored to these social groups. Educational programs also could provide salient information about the dangers of excessive alcohol consumption or changing social norms among networks regarding binge drinking. Intervention implications could be geared towards creating social media platforms and social environments conducive to participating in alcohol-free events, encouraging alcohol use in moderation, and integrating campaigns that change the current perception of binge drinking and cigarette use.

Lastly, providing targeted interventions that integrate multiple health behaviors would be useful for identified students with multiple health risk behaviors. Approximately $40 \%$ of the sample was in Class 2, characterized by the high likelihood of multiple health-damaging behaviors. More than half of the students in this group did not meet the recommendations for weekly physical activity and consistently reported poor dietary behaviors. Accordingly, students in this group may benefit most from obesity interventions that do not focus just on decreasing physical inactivity to reduce their obesity risk. Instead, the coupling of diet and physical activity programming might be most effective for this group. Intervention implications for this group include finding ways to motivate these students to become healthier. A participatory health course that teaches students how they can cook nu- 
tritious food, experience various forms of physical activity, and explore fun non-sedentary activities while building connections with others could be beneficial for this group. Anti-smoking and antibinge drinking campaigns also could be advantageous for the identified individuals.

These findings highlight important future research. Qualitative research would help target each of the classes to increase health-promoting behaviors. Suggestions can be put forth to address each of the health-related behaviors that have been found to be particularly risky for a specific group; however, for effective intervention development, formative research is recommended to uncover determinants of these co-occurring behaviors which may warrant different strategies. Formative research is particularly important for Class 1 and Class 2 to identify salient messages, interpersonal influences, and channels to disseminate programs.

\section{Conclusions}

The increased understanding of the prevalence and clustering patterns of multiple health-related behaviors is helpful in identifying subgroups of the population that are at particularly high risk for weight gain based on behavioral patterns. Understanding these typologies may help public health professionals create more effective and efficient interventions in community colleges by targeting certain behaviors or certain contexts to help reduce the onset and improve management of existing chronic diseases.

\section{Human Subjects Statement}

The Institutional Review Board of the University of Minnesota approved all aspects of the CHOICES research.

\section{Conflict of Interest Statement}

The authors of this article declare they have no conflicts of interest related to the submission of this manuscript.

\section{References}

1. Arnett JJ. Emerging adulthood. A theory of development from the late teens through the twenties. Am Psychol. 2000;55(5):469-480.

2. Sussman S, Arnett JJ. Emerging adulthood: developmental period facilitative of the addictions. Eval Health Prof.
2014;37(2):147-155.

3.Zimmermann-Sloutskis D, Wanner M, Zimmermann E, Martin BW. Physical activity levels and determinants of change in young adults: a longitudinal panel study. Int J Behav Nutr Phys Act. 2010;7:2.

4. O'Malley PM, Johnston LD. Epidemiology of alcohol and other drug use among American college students. $J$ Stud Alcohol Suppl. 2002;(14):23-39.

5. Nelson MC, Story M, Larson NI, et al. Emerging adulthood and college-aged youth: an overlooked age for weight-related behavior change. Obesity (Silver Spring). 2008;16(10):2205-2211.

6. National Center for Educational Statistics. Postsecondary environments and characteristics - characteristics of postsecondary students. Available at: http://nces.ed.gov/fastfacts/display.asp?id=372. Accessed December 19, 2017.

7. Mokdad AH, Marks JS, Stroup DF, Gerberding JL. Actual causes of death in the United States, 2000. JAMA. 2004;291(10):1238-1245.

8. Reeves MJ, Rafferty AP. Healthy lifestyle characteristics among adults in the United States, 2000. Arch Intern Med. 2005;165(8):854-857.

9. Pronk NP, Anderson LH, Crain AL, et al. Meeting recommendations for multiple healthy lifestyle factors. Prevalence, clustering, and predictors among adolescent, adult, and senior health plan members. Am J Prev Med. 2004;27(2 Suppl):S25-S33.

10. Ford ES, Ford MA, Will JC, et al. Achieving a healthy lifestyle among United States adults: a long way to go. Ethn Dis. 2001;11(2):224-231.

11. Breslau N. Psychiatric comorbidity of smoking and nicotine dependence. Behav Genet. 1995;25(2):95-101.

12. Nelson MC, Gordon-Larsen P, Adair LS, Popkin BM. Adolescent physical activity and sedentary behavior: patterning and long-term maintenance. Am J Prev Med. 2005;28(3):259-266.

13. van Nieuwenhuijzen $M$, Junger $M$, Velderman $M K$, et al. Clustering of health-compromising behavior and delinquency in adolescents and adults in the Dutch population. Prev Med. 2009;48(6):572-578.

14. Fine LJ, Philogene GS, Gramling R, et al. Prevalence of multiple chronic disease risk factors. 2001 National Health Interview Survey. Am J Prev Med. 2004;27(2 Suppl):18-24.

15. McTigue KM, Garrett JM, Popkin BM. The natural history of the development of obesity in a cohort of young U.S. adults between 1981 and 1998. Ann Intern Med. 2002;136(12):857-864.

16. Fothergill E, Guo J, Howard L, et al. Persistent metabolic adaptation 6 years after "The Biggest Loser" competition. Obesity (Silver Spring). 2016;24(8):1612-1619.

17. Nelson MC, Larson NI, Barr-Anderson D, et al. Disparities in dietary intake, meal patterning, and home food environments among young adult nonstudents and 2- and 4-year college students. Am J Public Health. 2009;99(7):1216-1219.

18. Laska M, Pasch K, Lust K, et al. The differential prevalence of obesity and related behaviors in two- vs. four-year colleges. Obesity (Silver Spring). 2011;19(2):453-456.

19. Collins LM, Lanza ST. Latent Class and Latent Transition Analysis: With Applications in the Social, Behavioral, and Health Sciences. New York, NY: Wiley; 2010:12-47. 
20. Héroux M, Janssen I, Lee DC, et al. Clustering of unhealthy behaviors in the aerobics center longitudinal study. Prev Sci. 2012;13(2):183-195.

21. Leventhal AM, Huh J, Dunton GF. Clustering of modifiable biobehavioral risk factors for chronic disease in US adults: a latent class analysis. Perspect Public Health. 2014;134(6):331-338.

22. Phelan JC, Link BG, Tehranifar P. Social conditions as fundamental causes of health inequalities: theory, evidence, and policy implications. I Health Soc Behav. 2010;51(Suppl): S28-S40.

23. Bancroft C, Joshi S, Rundle A, et al. Association of proximity and density of parks and objectively measured physical activity in the United States: a systematic review. Soc Sci Med. 2015;138:22-30.

24. Smalls BL, Gregory CM, Zoller JS, Egede LE. Assessing the relationship between neighborhood factors and diabetes related health outcomes and self-care behaviors. $B M C$ Health Serv Res. 2015;15:445.

25. Hughes ME, Waite LJ. Health in the household context: living arrangements and health in late middle age. $J$ Health Soc Behav. 2002;43(1):1-21.

26. Wechsler H, Lee JE, Nelson TF, Kuo M. Underage college students' drinking behavior, access to alcohol, and the influence of deterrence policies. Findings from the Harvard School of Public Health College Alcohol Study. J Am Coll Health. 2002;50(5):223-236.

27. Satalic Z, Baric IC, Keser I. Diet quality in Croatian university students: energy, macronutrient and micronutrient intakes according to gender. Int J Food Sci Nutr. 2007;58(5):398-410.

28. Beasley LJ, Hackett AF, Maxwell SM. The dietary and health behaviour of young people aged 18-25 years living independently or in the family home in Liverpool, UK. Int J Consum Stud. 2004;28(4):355-363.

29. Jones DH, Harel Y, Levinson RM. Living arrangements, knowledge of health risks, and stress as determinants of health-risk behavior among college students. J Am Coll Health. 1992;41(2):43-48.

30. Galambos NL, Tilton-Weaver LC. Multiple-risk behaviour in adolescents and young adults. Health Rep. 1998;10(2):9-20.

31. Rossow I, Rise J. Living arrangements and health behaviors in adolescents and young adulthood. Health Educ Res. 1993;8(4):495-503.

32. Jones DH, Harel Y, Levinson RM. Living arrangements, knowledge of health risks, and stress as determinants of health-risk behavior among college students. J Am Coll Health. 1992;41(2):43-48.

33. Umberson D. Family status and health behaviors: social control as a dimension of social integration. J Health Soc Behav. 1987;28(3):306-319.

34. Ross CE, Mirowsky J, Goldsteen K. The impact of the family on health: the decade in review. J Marriage Fam. 1990;52(4):1059-1078.

35. Lytle LA, Moe SG, Nanney MS, et al. Designing a weight gain prevention trial for young adults: the CHOICES study. Am J Health Educ. 2014;45(2):67-75.

36. Bandura A. Health promotion by social cognitive means. Health Educ Behav. 2004;31(2):143-164.

37. Nelson MC, Lytle LA. Development and evaluation of a brief screener to estimate fast food and bever- age consumption among adolescents. I Am Diet Assoc. 2009;109(4):730-734.

38. Raynor DA, Phelan S, Hill JO, Wing RR. Television viewing and long-term weight maintenance: results from the National Weight Control Registry. Obesity (Silver Spring). 2006;14(10):1816-1824.

39. Paffenbarger RS Jr, Wing AL, Hyde RT. Physical activity as an index of heart attack risk in college alumni. Am J Epidemiol. 1978;108(3):161-175.

40. World Health Organization. Global Physical Activity Questionnaire Version 2. 2017. Available at: http://www. who.int/chp/steps/GPAQ. Accessed December 10, 2017.

41. French SA, Jeffery RW, Murray D. Is dieting good for you? Prevalence, duration and associated weight and behaviour changes for specific weight loss strategies over four years in US adults. Int J Obes Relat Metab Disord. 1999;23(3):320-327.

42. US Centers for Disease Control and Prevention (CDC). State-specific secondhand smoke exposure and current cigarette smoking among adults - United States, 2008. MMWR Morb Mortal Wkly Rep. 2009;58(44):1232-1235.

43. National Institute of Alcohol Abuse and Alcoholism (NIAAA). NIAAA council approves definition of binge drinking. NIAAA Newsletter, No. 3, Winter 2004. Available at: pubs.niaaa.nih.gov/publications/Newsletter/winter2004/Newsletter_Number3.pdf. Accessed December $19,2017$.

44. Duffey KJ, Gordon-Larsen P, Jacobs DR Jr, et al. Differential associations of fast food and restaurant food consumption with 3-y change in body mass index: the Coronary Artery Risk Development in Young Adults Study. Am J Clin Nutr. 2007;85(1):201-208.

45. Brown AW, Bohan Brown MM, Allison DB. Belief beyond the evidence: using the proposed effect of breakfast on obesity to show 2 practices that distort scientific evidence. Am J Clin Nutr. 2013;98(5):1298-1308.

46. Malik VS, Popkin BM, Bray GA, et al. Sugar-sweetened beverages and risk of metabolic syndrome and type 2 diabetes: a meta-analysis. Diabetes Care. 2010;33(11):24772483.

47. US Department of Health and Human Services. 2008 Physical Activity Guidelines for Americans. 2008. Available at: https:/health.gov/paguidelines/guidelines/chapter1.aspx/. Accessed December 19, 2017.

48. Dunstan DW, Salmon J, Owen N, et al. Associations of TV viewing and physical activity with the metabolic syndrome in Australian adults. Diabetologia. 2005;48(11):2254-2261.

49. Salmon J, Bauman A, Crawford D, et al. The association between television viewing and overweight among Australian adults participating in varying levels of leisuretime physical activity. Int J Obes Relat Metab Disord. 2000;24(5):600-606.

50. Warren TY, Barry V, Hooker SP, et al. Sedentary behaviors increase risk of cardiovascular disease mortality in men. Med Sci Sports Exerc. 2010;42(5):879-885.

51. Ding D, Gebel K, Phongsavan P, et al. Driving: a road to unhealthy lifestyles and poor health outcomes. PLoS One. 2014;9(6):e94602.

52. Chomistek AK, Manson JE, Stefanick ML, et al. Relationship of sedentary behavior and physical activity to incident cardiovascular disease: results from the Women's 
Health Initiative. J Am Coll Cardiol. 2013;61(23):23462354.

53. Vandelanotte C, Sugiyama T, Gardiner P, Owen N. Associations of leisure-time internet and computer use with overweight and obesity, physical activity and sedentary behaviors: cross-sectional study. J Med Internet Res. 2009;11(3):e28.

54. PROC LCA \& PROC LTA Version 1.3.2. University Park, PA: The Methodology Center, Penn State University. 2015. Available at: http://methodology.psu.edu. Accessed November 21, 2016.

55. Akaike H. A new look at the statistical model identification. IEEE Trans Autom Control. 1974; 19(6):716-723.

56. Schwarz G. Estimating the dimension of a model. Ann Stat. 1978;6(2):461-464.

57. Celeux G, Soromenho G. An entropy criterion for assessing the number of clusters in a mixture model. $J$ Classif. 1996;13(2):195-212.

58. Lanza ST, Collins LM, Lemmon DR, Schafer JL. PROC LCA: A SAS procedure for latent class analysis. Struct Equ Modeling. 2007;14(4):671-694.
59. Collins LM, Lanza ST. Latent Class and Latent Transition Analysis: With Applications in the Social, Behavioral, and Health Sciences. New York, NY: Wiley; 2010: 51-110.

60. Bray BC, Lanza ST, Tan X. An introduction to eliminating bias in classify-analyze approaches for latent class analysis. Struct Equ Modeling. 2015;22(1):1-11.

61. Kang J, Ciecierski CC, Malin EL, et al. A latent class analysis of cancer risk behaviors among U.S. college students. Prev Med. 2014;64:121-125.

62. Schüz B, Bower J, Ferguson SG. Stimulus control and affect in dietary behaviours. an intensive longitudinal study. Appetite. 2015;87:310-317.

63. Ferguson SG, Shiffman S, Dunbar M, Schüz N. Higher stimulus control is associated with less cigarette intake in daily smokers. Psychol Addict Behav. 2016;30(2):229-237.

64. Moe SG, Lytle LA, Nanney MS, et al. Recruiting and retaining young adults in a weight gain prevention trial: lessons learned from the CHOICES study. Clin Trials. 2016;13(2):205-213.

65. Yee N. Motivations for play in online games. Cyberpsychol Behav. 2006;9(6):772-775. 